Portland State University

PDXScholar

$10-2013$

\title{
Data-Driven Illustrations for Climate Smart Communities Scenarios
}

\author{
Nancy Yen-wen Cheng \\ University of Oregon \\ Kim Ellis \\ Metro \\ Molly Vogt \\ Metro \\ Clint Chiavarini \\ Transportation Research and Education Consortium \\ Justin Houk \\ Transportation Research and Education Consortium
}

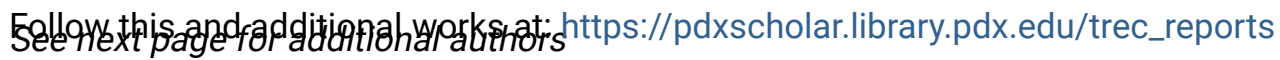

Part of the Environmental Policy Commons, Transportation Commons, and the Urban Studies and Planning Commons

Let us know how access to this document benefits you.

\section{Recommended Citation}

Cheng, Nancy Yen-wen, Kim Ellis, Molly Vogt, Clint Chiavarini, Justin Houk, Brian Lockyear, Boyce Postma, and Peggy Morell. Data-Driven Illustrations for Climate Smart Communities Scenarios. OTREC-SS-728. Portland, OR: Transportation Research and Education Center (TREC), 2013. https://doi.org/10.15760/ trec.57

This Report is brought to you for free and open access. It has been accepted for inclusion in TREC Final Reports by an authorized administrator of PDXScholar. Please contact us if we can make this document more accessible: pdxscholar@pdx.edu. 


\section{Authors}

Nancy Yen-wen Cheng, Kim Ellis, Molly Vogt, Clint Chiavarini, Justin Houk, Brian Lockyear, Boyce Postma, and Peggy Morell 


\section{SOTREC}

FINAL REPORT

\section{Data-Driven Illustrations for Climate Smart Communities Scenarios}

OTREC-SS-728

October 2013 



\title{
DATA-DRIVEN ILLUSTRATIONS FOR CLIMATE SMART COMMUNITIES SCENARIOS
}

OTREC-SS-728

\author{
by \\ Nancy Yen-wen Cheng \\ University of Oregon \\ Kim Ellis \\ Metro \\ Molly Vogt \\ Metro
}

and Clint Chiavarini, Justin Houk, Brian Lockyear, Boyce Postma, and Peggy Morell

for

\begin{abstract}
Oregon Transportation Research
and Education Consortium (OTREC)

P.O. Box 751

Portland, OR 97207
\end{abstract}

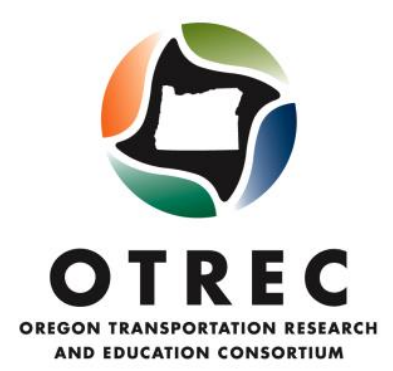

October 2013 



\section{Technical Report Documentation Page}

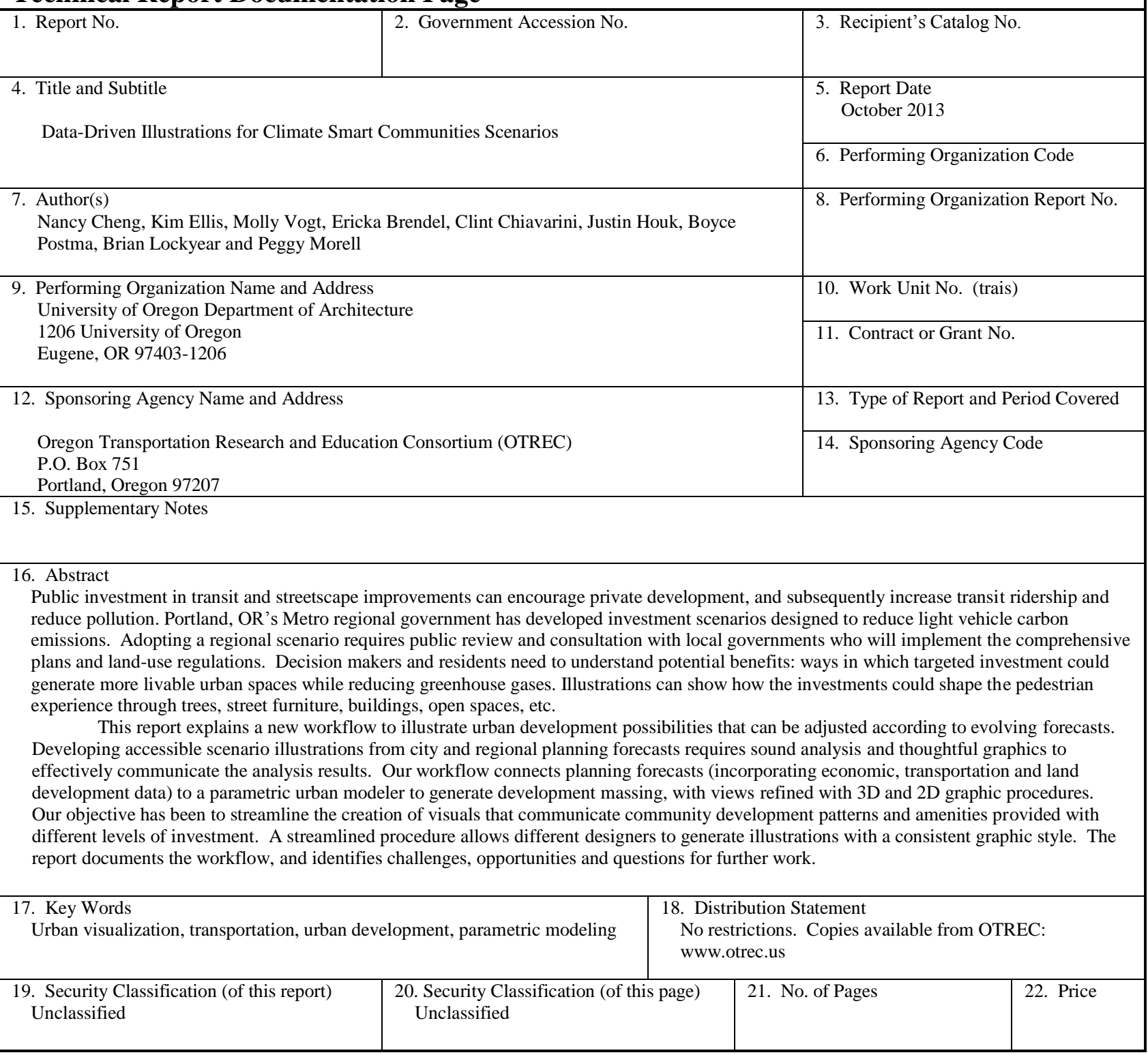






\section{ACKNOWLEDGEMENTS}

This project was funded by the Oregon Transportation Research and Education Consortium (OTREC). In addition to the authors, contributors to the project include Metro staff Paul Couey, Alan Gunn, Matthew Hampton, and Janice Larson. Technical advice was provided by ESRI personnel including Shannon McElvaney, Sean Morrish, and John Sharrard. We would like to thank UO A\&AA Dean Frances Bronet, Architecture head Judith Sheine, former Metro Research Center Director Mike Hoglund, former Metro Planning and Development Director Robin McArthur, and former Metro Planning Manager Christina Deffebach for their encouragement and support.

\section{DISCLAIMER}

The contents of this report reflect the views of the authors, who are solely responsible for the facts and the accuracy of the material and information presented herein. This document is disseminated under the sponsorship of the U.S. Department of Transportation University Transportation Centers Program in the interest of information exchange. The U.S. Government assumes no liability for the contents or use thereof. The contents do not necessarily reflect the official views of the U.S. Government. This report does not constitute a standard, specification, or regulation. 



\section{TABLE OF CONTENTS}

EXECUTIVE SUMMARY ............................................................................................................ 1

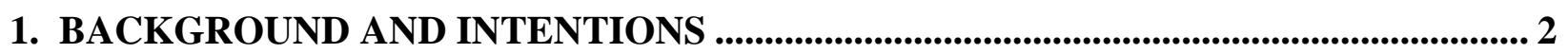

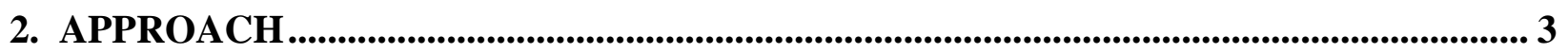

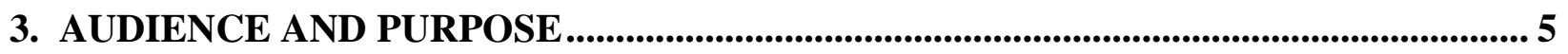

4. GRAPHIC PROCESSES AND CHALLENGES....................................................................... 5

5. CONNECTING BUILDING DEVELOPMENT TO JOB AND HOUSING

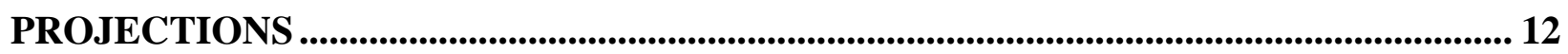

6. ISSUES: PLACE SPECIFICITY, PLANNING ABSTRACTION AND SOFTWARE

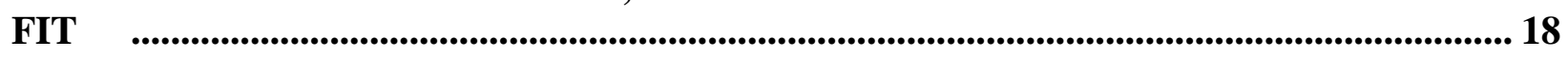

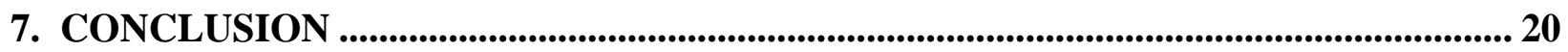

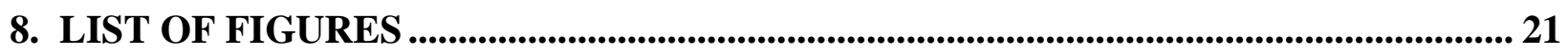

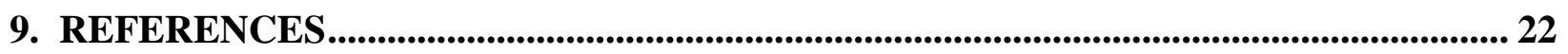






\section{EXECUTIVE SUMMARY}

Public investment in transit and streetscape improvements can encourage private development, and subsequently increase transit ridership and reduce pollution. Portland OR's Metro regional government has developed investment scenarios designed to reduce light vehicle carbon emissions. Adopting a regional scenario requires public review and consultation with local governments who will implement the comprehensive plans and land-use regulations. Decision makers and residents need to understand potential benefits: ways in which targeted investment could generate more livable urban spaces while reducing greenhouse gases. Illustrations can show how the investments could shape the pedestrian experience through trees, street furniture, buildings, open spaces, etc.

This report explains a new workflow to illustrate urban development possibilities that can be adjusted according to evolving forecasts. Developing accessible scenario illustrations from city and regional planning forecasts requires sound analysis and thoughtful graphics to effectively communicate the analysis results. Our workflow connects planning forecasts (incorporating economic, transportation and land development data) to a parametric urban modeler to generate development massing, with views refined with 3D and 2D graphic procedures. Our objective has been to streamline the creation of visuals that communicate community development patterns and amenities provided with different levels of investment. A streamlined procedure allows different designers to generate illustrations with a consistent graphic style. The report documents the process of creating data-driven illustrations using ESRI ArcGIS, ESRI CityEngine, Sketchup; then identifies challenges, opportunities and questions for further work. 


\section{BACKGROUND AND INTENTIONS}

Governments can help reduce greenhouse gas emissions by investing in urban centers, corridors and employment areas in ways that attract private development of pedestrian and bicyclingfriendly communities. Investments can take the form of providing services and shopping near where people live, expanding transit service, managing parking and providing safer routes for walking and biking and other tools. Removing barriers to more efficient use of land and existing infrastructure can also help local governments achieve their desired community visions.

The Climate Smart Communities Scenarios Project was initiated in response to a mandate from the 2009 Oregon Legislature to develop a strategy to reduce greenhouse gas emissions from cars and small trucks by 2035 . The goal of the CSC project is to adopt a preferred approach that meets the state mandate and supports community visions for downtowns, main streets and employment areas.

To better understand how best to support community visions and reduce greenhouse gas emissions, Metro evaluated three approaches - or scenarios - to investing in locally adopted landuse and transportation plans and policies, and evaluated the impact of those investments on how the region grows over the next 25 years. The analysis results will be used to frame a regional discussion about which investments and actions should be included in a preferred approach for the Metro Council to consider for adoption in December 2014. Sound analysis and informative graphics are needed to effectively communicate the results of the analysis to help policymakers and the public understand the tradeoffs and benefits associated with different investments.

This research project is focused on the development of informative and accessible illustrations of combined transportation and land development strategies that yield different levels of greenhouse gas emission reductions. Illustrations of the scenarios tested were intended to help policymakers and other stakeholders better understand the potential on-the-ground impacts of each scenario.

The project team researched several processes to create visualizations and illustrations that can be updated and adjusted to reveal alternative development possibilities that reflect forecasted growth. Our workflow uses city and regional growth distribution forecasts to generate possible urban development massing, with views refined with 3D and 2D graphic procedures. The goals include streamlining the creation of visuals that communicate urban form and street design provided with different levels of investment, and defining a procedure that allows different designers to step in during the life of a project and create a set of illustrations that has a consistent graphic style. This report documents the approach taken, describes the recommended workflow, and identifies challenges and questions for further work.

The project has provided an important opportunity to build on Metro's leadership in planning, mapping and data analysis with the University of Oregon's (UO) architectural graphics proficiency. It has served to build relationships for future collaborations between the UO's 
Architecture Department, Metro's Data Resource Group (DRC) and Climate Smart Communities (CSC) Scenarios project team, the City of Portland's Bureau of Planning and Sustainability (PBPS) and ESRI CityEngine software developers (ESRI CE).

\section{APPROACH}

The Metro CSC team worked with regional advisory committees, community and business leaders, and other stakeholders to develop three scenarios to evaluate during the summer of 2013:

Scenario A - Recent Trends - This scenario is a projection of how the region would grow if current local government transportation and land-use plans are followed through to 2035 with existing revenues and policies.

Scenario B - Adopted Plans - This scenario is a projection of how the region would grow if current local government transportation and land-use plans are followed through to 2035 with the revenues anticipated in the 2035 Regional Transportation Plan.

Scenario C - New Plans and Policies - This scenario is a projection of how the region would grow if current local government transportation and land-use plans are followed through in addition to implementing the emerging Southwest Corridor land-use vision and pursuing more investment throughout the region.

Scenario B - adopted plans for increased investment - has been calibrated to adopted land-use plans and a regionally developed, local-government-reviewed household and employment forecast adopted by the Metro Council in November 2012. The data from this project results from state-of-the-art models that calculate greenhouse gas emissions, regional travel, and the growth and distribution of households and jobs.

The Scenario B and Scenario C data has been translated into color-coded maps using Fregonese Associates' Envision Tomorrow ArcGIS-based Scenario Builder, an urban and regional planning sketch-planning tool used to develop and evaluate land-use growth scenarios. Land-use Development Types (Dev Types) were defined as percentages of building types (such as office, industrial, multifamily residential and mixed use) and typical building heights in number of stories. Development Types were assigned to 264 -foot two-grid cells by painting on color-coding as consequences of the transportation and land-use policy directives. Envision Tomorrow calculates each grid cell's capacity for housing units and jobs (among other possible measures). This allows planners to correlate growth distribution scenarios to numbers of housing units and jobs that could be accommodated. 

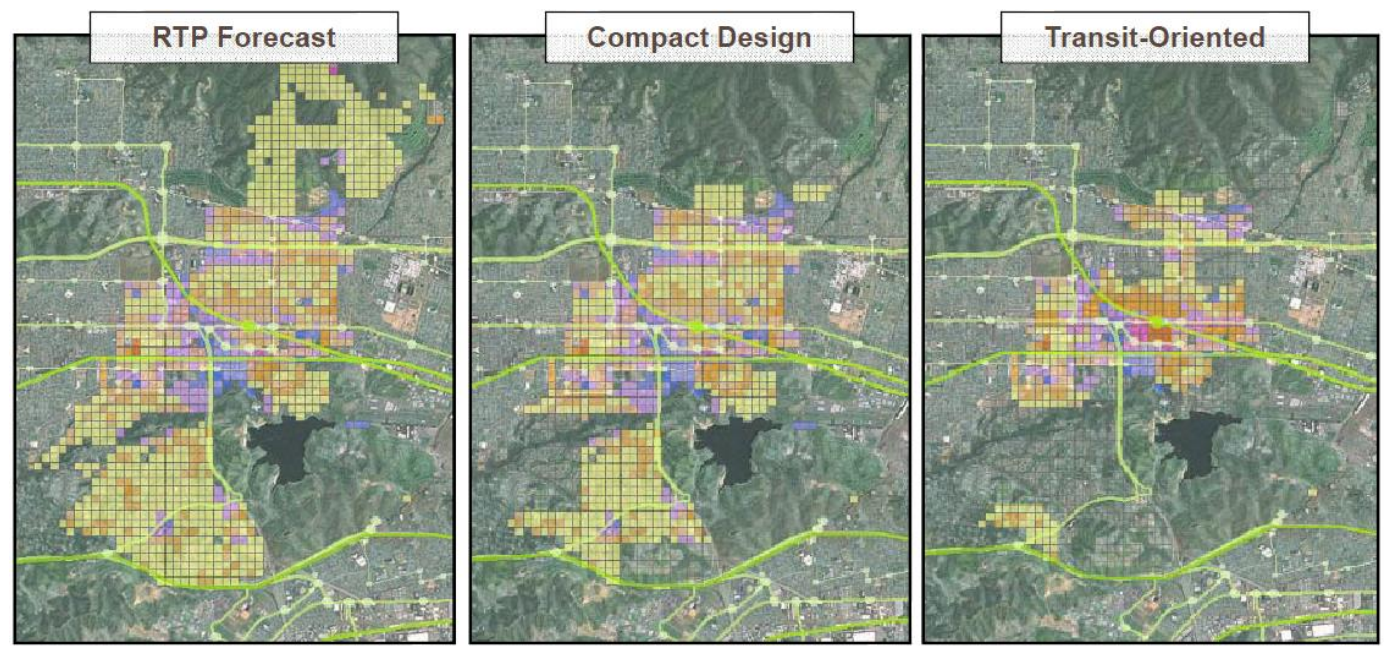

Figure 1: Fregonese Associates' Envision Tomorrow allows planners to paint Development Types onto map grid cells.

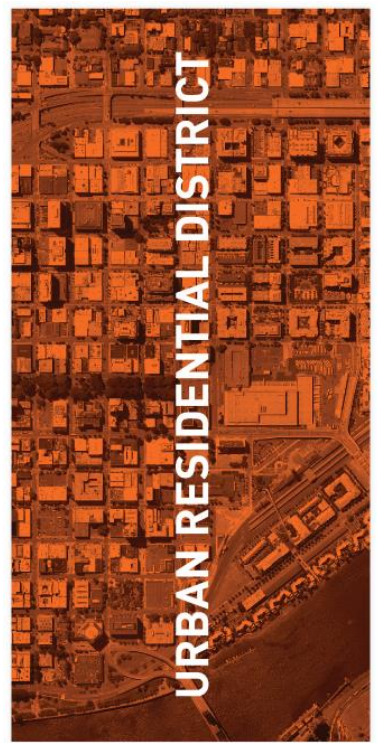

URBAN RESIDENTIAL DISTRICT
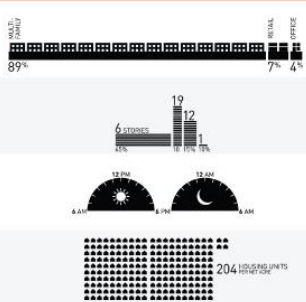

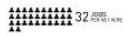

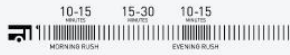

$\$ \$ \$ \$$

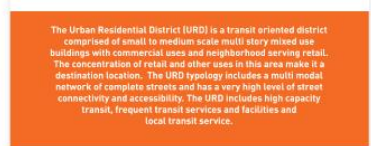

Figure 2: Each Development Type corresponds to specific proportions of building types, building height, number of housing units and jobs, and transit activity. Graphic cards by Ryan Sullivan of Paste in Place graphics.

This development capacity was subsequently reviewed by city and county staff and then modeled using MetroScope, another planning tool utilized by Metro's Data Resource Center to support the Climate Smart Communities Scenarios Project. MetroScope forecasts growth distributions through the interplay of market forces with land-use policies and transportation. MetroScope takes into account economic trends (employment by industry class) and demographic trends (households by size, income and age bracket); local zoning and planned capacity; an inventory of buildable land; real estate value/prices; urban reserves supply; system development charges; and other development factors to estimate future household and employment growth and distribution in the region. 


\section{AUDIENCE AND PURPOSE}

From these broad planning forecasts, the team's job has been to translate how the growth scenarios would look in a particular district on the ground. Planning data is often abstract and challenging to understand, so the illustrations are intended to help communicate the results of the evaluation to stakeholders so they may provide input on what strategies and investments they support for their community.

Illustrations can help planners, policymakers and the public develop a common understanding about how policies could affect specific places. For example, transforming vacant land or surface parking lots into new retail or services served by transit and building new sidewalks and bicycle routes can help create a vibrant, pedestrian-friendly environment. Illustrations can make these possibilities legible, and build support for these investments and other policies such as retrofitting streetscapes to include street lighting, street trees and planting beds.

A wide variety of stakeholders were identified through the research process, creating the need for different types of visualizations. Some of these stakeholders include taxpayers, local government officials, GIS data specialists, state government officials, and local business owners. Each stakeholder would likely require a slightly different variation of the graphic that would be easiest to read. For example, a mayor might want to look at new development from an aerial view, providing a quick grasp of the complete implications of development on a district or city level, while a small-business owner might want to see what that development means in terms of modified access to the street or public transportation. Both are equally relevant, but require a different type of illustration.

Many styles and concepts for visualizations were discussed in the early phases of the project, including simple cartoony city graphics, detailed realistic renderings, data-centered visualizations that read as infographics, simple color-coded 3D blocks, and some combination of these communication tools. Because the research has emphasized exploring alternatives rather than producing finished renderings, no definitive style for this work was identified. Instead, a description of the graphic workflow and sample images were developed for further exploration at a later date.

\section{GRAPHIC PROCESSES AND CHALLENGES}

Planners and GIS professionals often develop, store and analyze planning schemes in databases that have spreadsheet user interfaces, which can generate two-dimensional map graphics. The purpose of this research is to make this data accessible and legible to a wider audience through three-dimensional illustrations.

It was first necessary to understand the tools that were available and how they might work together to produce a relatively simple workflow process, allowing for future usability. ESRI's CityEngine was the first tool under investigation, a 3-D procedural modeling and visualization 
software designed to work within a GIS environment. We received input and suggestions from many people at ESRI throughout the development of this research, and it should be noted that without their feedback and support the research would have been impossible to complete.

CityEngine (CE) can be used to visualize an existing place utilizing GIS data and to visualize new places based on desired parameters and quantitative urban form characteristics. The primary strength of the software and reason for its use in this research is its unique ability to create adjustable urban environments through parametric procedural modeling. This means that many buildings, roads and urban elements created within the visualization are controlled through geometric rules programmed by the author, as opposed to piece-wise development of individual geometric elements. This is powerful because it allows for dynamic change of many individual model elements to reflect changes in the development parameters.

For example, creating a building in CE does not require extruding a box and punching windows in the box as in typical 3D modeling software such as Trimble Sketchup (SU), or Autodesk 3DS MAX. Instead, creating a building in CE requires writing a set of operations in the procedural language known as .CGA scripting. To grow a building, the footprint of the box is copied vertically for a specific number of floors, then the faces of the box are split into bays, windows and door areas. When a building is created this way, options can be developed in the code to allow for geometric manipulations via changes to the code, the built-in properties "slider bars."

Production of a single building through code would be inefficient - writing code requires understanding the syntax and programming language, and is less intuitive than a graphical user interface. However, producing many buildings - across a neighborhood, district or city becomes much more efficient using code-based automation. In contrast to manual manipulation, where each building takes the same amount of time to produce and adds up over a modeled site, in code-based modeling a single line of code many be edited to increase the number of buildings from one to 15 or 500. If you wanted to create a city made of boxes with 4'2" widows, and then later decide that actually you want them slightly larger, it would take hours in a typical static modeler such as SU or 3DS Max. But with a dynamic modeler, the change is instantaneous. This software was the obvious choice for creating rapid visualizations for the data that already existed in the GIS world.

The original intention was to develop all elements of place through CE and export it to rendering software such as 3DS Max or Kerkythea (Kerky) via SU, followed by Photoshop and distribution. This would allow for relatively low graphics skills to create visualizations in a semirapid manner, with extreme ease of manipulation dictated by data variations.

Graphic workflows in the research process are described below.

\subsection{CITYENGINE AS THE PRIMARY MODELLER}

Initially, there was a serious investment in learning CE to develop and export entire city scenes for rendering. The software workflow functioned well in creating new urban regions, and generated more geometric conflicts and bugs when used with existing GIS data or modeling 
places with lots of open space in between landmarks. As the software interface matures, this approach should be further explored in the future, as seen in robust vendor examples.

Strengths:

- Can lead to more efficient workflow.

- Less software to learn.

- Potential to create code that very quickly models a wide variety of place types with ease.

- Future integration with ESRI software.

- Excellent at modeling dense urban environments based on lot parameters.

Weaknesses:

- Requires more deep time investment to fully develop a parametric neighborhood.

- Poor at modeling less dense environments where buildings have a loose relationship with the lot shape.

- Does not relate multiple geometries. All geometry manipulation must take place within one object.

- Does not fill gaps in GIS database.

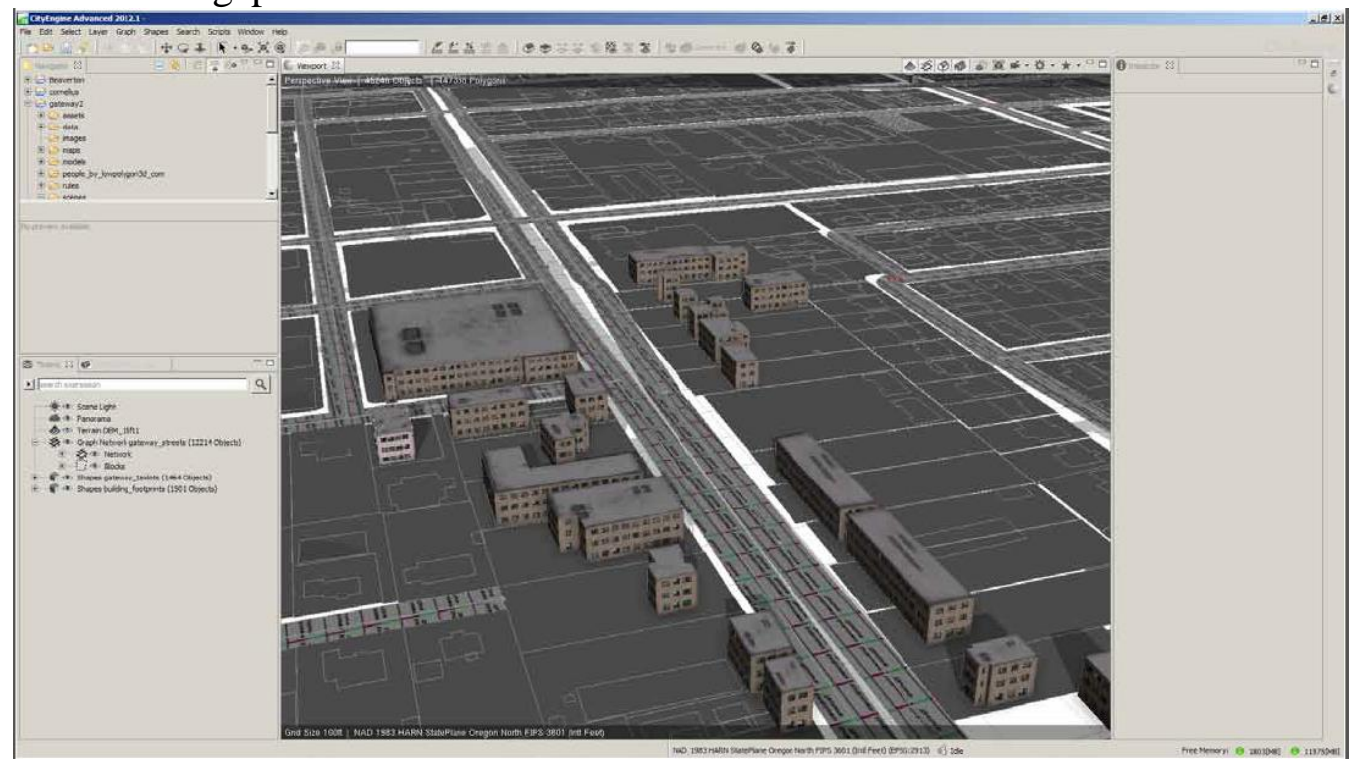

Figure 3. CityEngine uses rules to generate streets from street centerlines and buildings from lot footprints, leaving gaps from setbacks and right-of-ways.

\subsection{CITYENGINE BUILDINGS WITH GOOGLE EARTH BASE MODEL}

To facilitate quick, accurate building placement, we tested Google Earth as a model platform, exporting parts of the CE model as .KMZ files (typically buildings only). If the original GIS data is georeferenced, all procedurally modeled CE geometries are also georeferenced and on import to Google Earth are automatically placed accurately. For East Portland's Gateway district, we created roughly a dozen buildings sized according to MetroScope data and a recent Urban Design plan (PDC, 2012), then imported these directly into Google Earth. They appeared in their correct places on the 2D map. Using Google Earth's 3D environment created by LIDAR 
lightfield scanning, the buildings created in CE fit right into their existing surroundings. Screenshots were then taken and cleaned up in Photoshop.

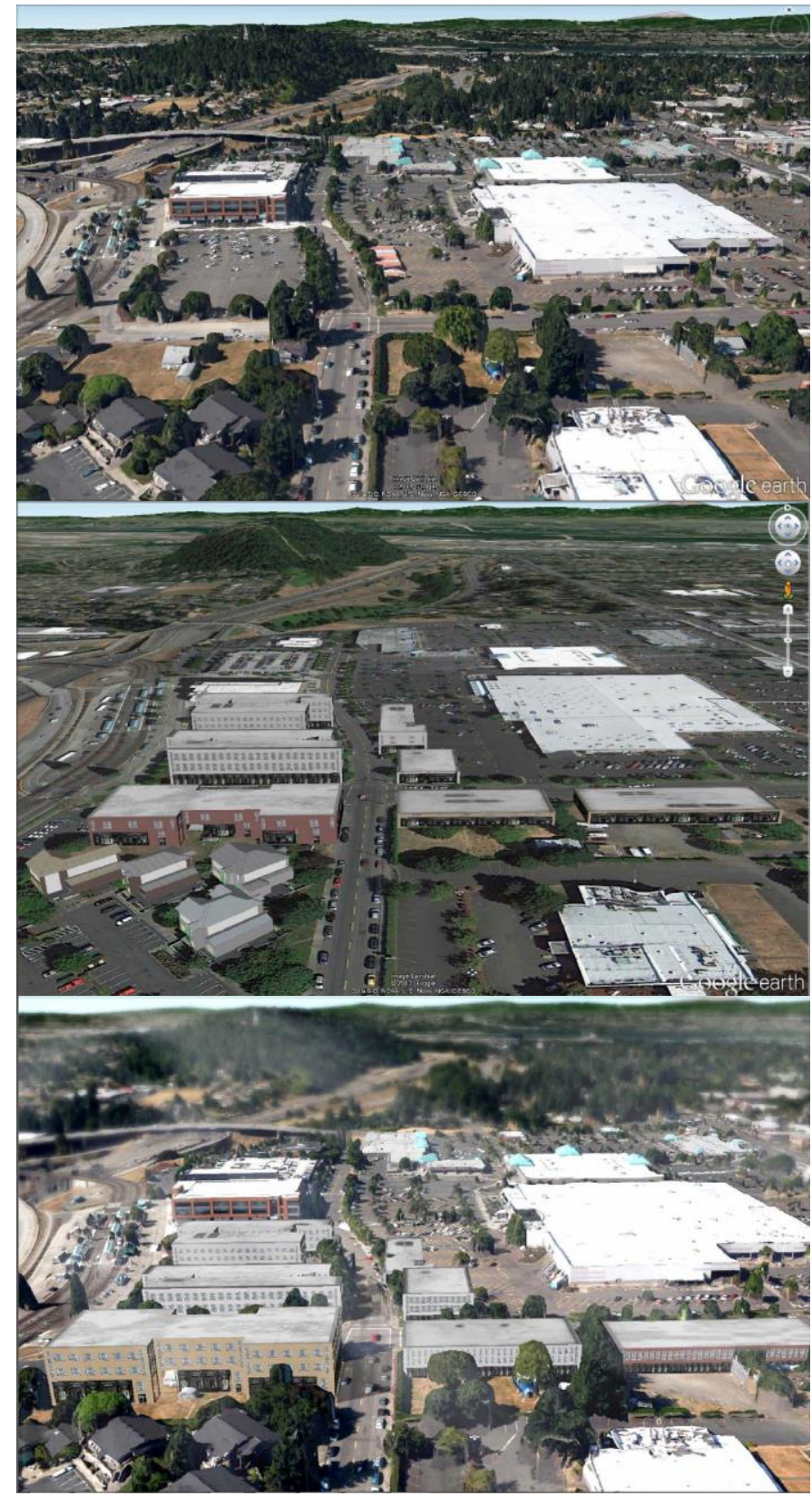

Figure 4: Google Earth image of existing land (top) with CityEngine buildings (middle) and Photoshop (bottom).

\section{Strengths:}

- Extremely easy once models are built in CE.

- Georeferenced, so no placement is necessary.

- Batches imports.

- Good quality of satellite photo and export resolution (with Google Earth PRO).

- Easy to create Photoshop scripts for some entourage since resolution is constant.

- Excellent background visuals for aerial perspectives with the built-in topography toggle. 
Weaknesses:

- The source LIDAR data used for this area was inconsistent - many parts of the scene had erroneous elevations.

- Geometry conflict - This method really only works well for building on what exists, as the geometries you import will simply be placed over the existing geometries. This is especially true of trees, which will often appear to be emerging from imported geometries.

- In some cases, may require extensive Photoshop manipulation.

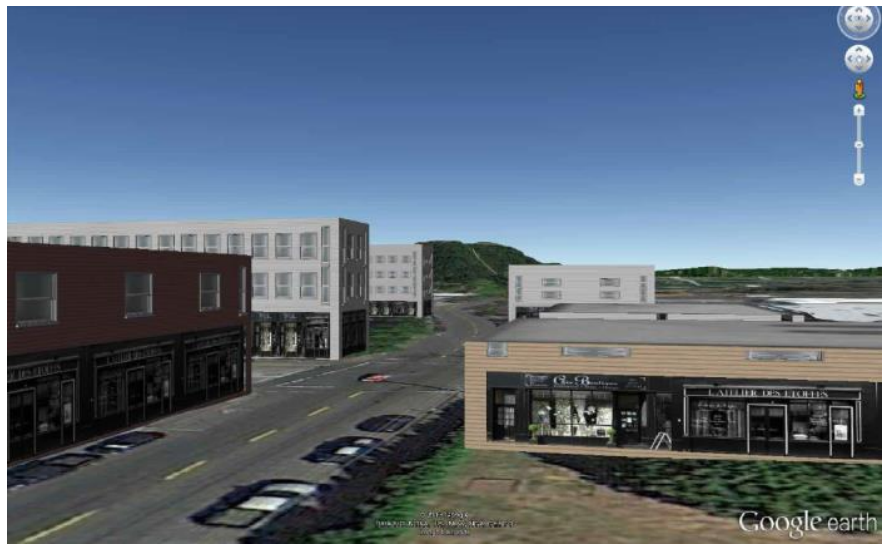

Figure 5: Pedestrian street-level views exaggerate distortions of site photos captured from above and require supplementary foreground information. Right foreground shows unrealistic covered tree canopy.

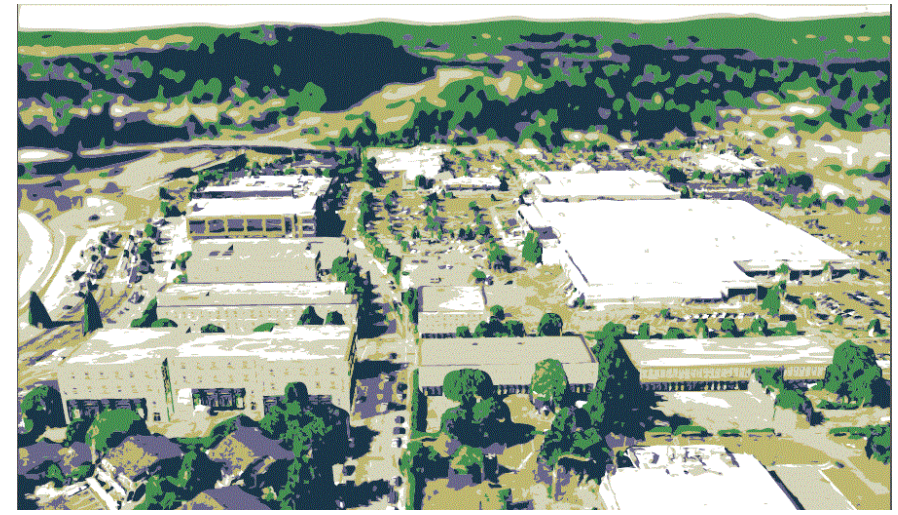

Figure 6: Non-photorealistic illustration effects can be created by post-processing the images. Limited control over edge precision makes the techniques less appropriate for illustrating buildings. (See work of Dr. Jürgen Döllner and David Salesin.)

\subsection{CITYENGINE BUILDINGS WITH SKETCHUP SITE DEVELOPMENT}

Because CE uses geometric rules to create streets, blocks, buildings and other urban elements, it works efficiently and precisely when creating new cities. Results were messier using CE to 
generate forms from real-world GIS data. Immediately, technical complexities became apparent: the auto-generated world of the parametric roads and buildings did not fit perfectly with the existing GIS data. For example, lot easements and setbacks created gaps between the idealized sidewalks and building facades. Additionally, the machine would sometimes hang due to the large volume of data.

To avoid these gaps and other site geometry challenges, we exported CE's parametrically generated buildings into a clean base model created in Sketchup from the GIS maps. Due to the small data involved, export of individual buildings could be done much more consistently than export of a large urban neighborhood.

The automatically generated CE buildings can be just one layer of information in a 3D visualization that can also include streets, vegetation, sky, background, and entourage such as scale figures and vehicles. To complement the CE buildings, a 3D streetscape "toolkit" of linear street, swale, sidewalk and other amenities was developed in Sketchup. This toolkit allows quick, consistent modeling of pedestrian-friendly urban streets, as the model elements can be placed onto a base aerial image. The elements of the toolkit are taken from the 2002 Metro design guidelines. Buildings from CE could then be placed in their appropriate locations, and the image exported to rendering software. From there, edits in Photoshop, adding the additional layers of information, can create a visually interesting image.
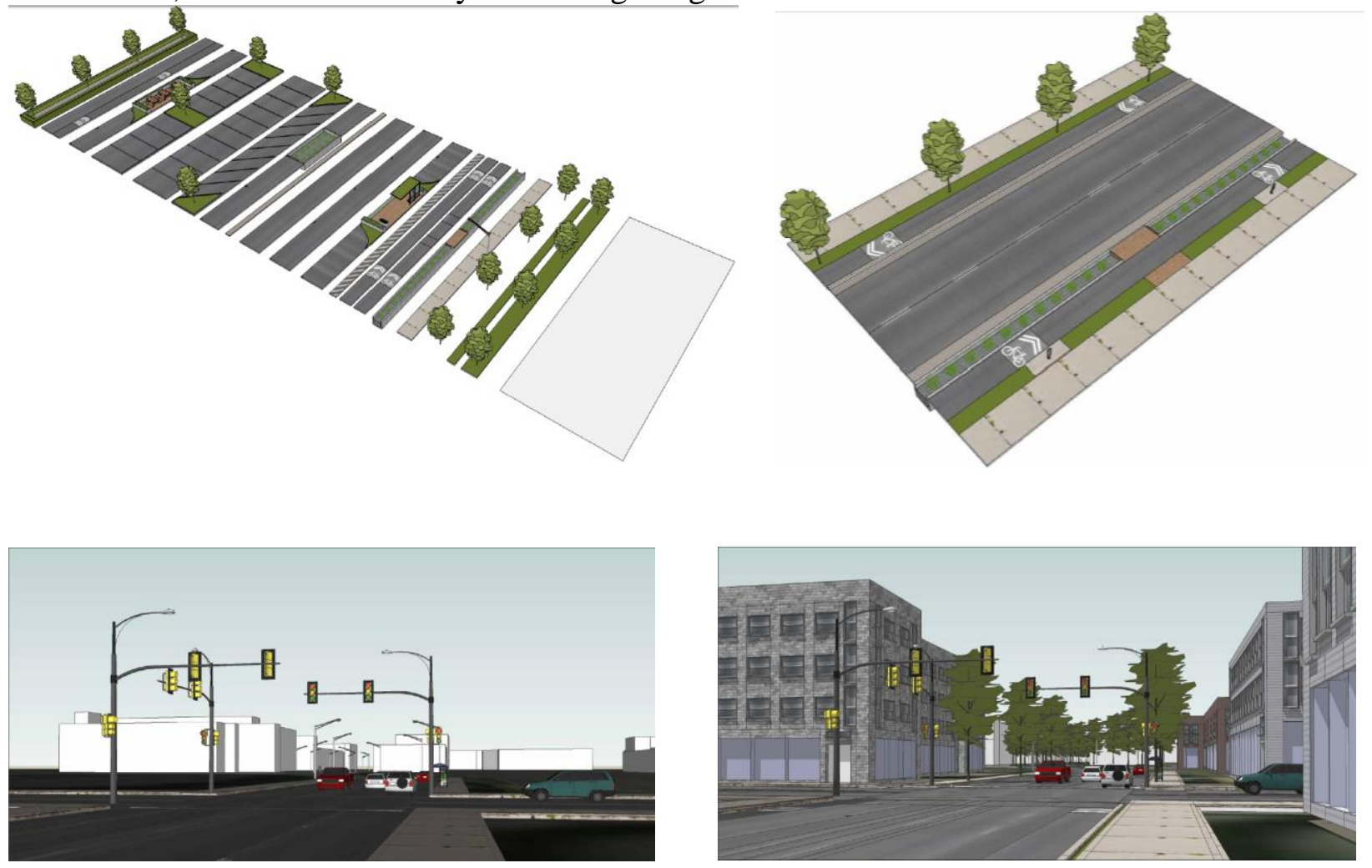

Figure 7: Streetscape toolkit provides linear components for pedestrian-friendly green streets. 


\section{Strengths:}

- Strong aesthetic control of the final product.

- Accessible modeling environment allows integration of third-party visualization tools. Weaknesses:

- Illustrations cannot contain parametric elements or be interactively data-driven.

While moving the 3D model from CityEngine to Sketchup makes the interactive "data-driven" aspect of visualizations one step removed, the Sketchup platform provides an accessible level of modeling control and refinement. Though this process does not truly merge the worlds of GIS databases and compelling 3D renderings, it gets close to some of the projects goals and certainly illuminates the path forward. In the future, these streetscape toolkits could be turned into parametric objects within CityEngine for automatic deployment, though it would not address the challenge of gaps between the idealized street definition and the complex reality of lot boundaries.
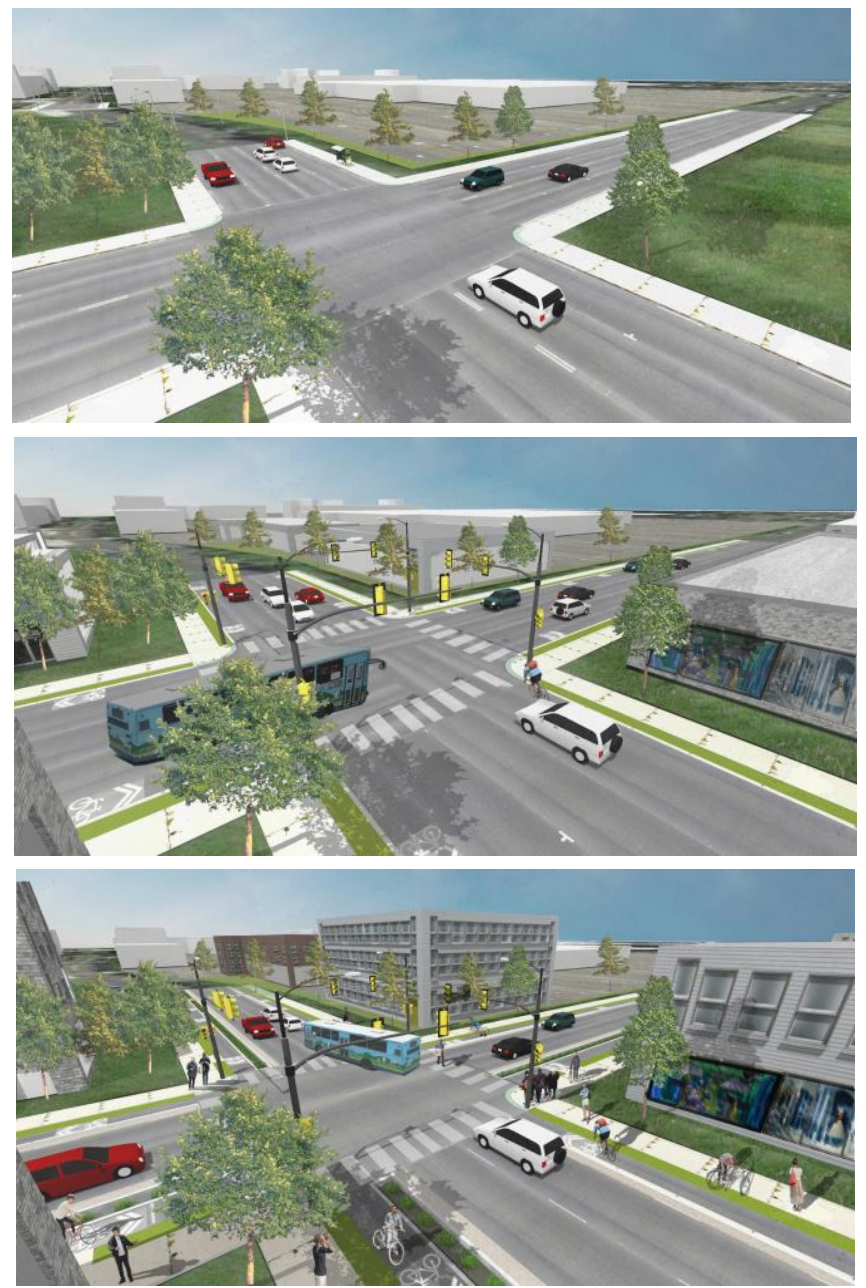

Figure 8: Scenarios A, B \& C with CityEngine buildings and streetscape elements. Lifting the viewpoint off the ground shows spatial organization better than ground-level perspectives. 


\section{CONNECTING BUILDING DEVELOPMENT TO JOB AND HOUSING PROJECTIONS}

\subsection{DATA-DRIVEN WORKFLOW}

In addition to looking at the graphics workflow, we separately examined how to make the Envision Tomorrow Development types drive the urban massing in CE. The intention was to use the Development Type categories assigned to grid cells in Envision Tomorrow to define and grow appropriate building types until we hit the target job and housing numbers. The steps include:

1. Generate massing of existing buildings from the GIS data.

2. Identify building lots ripe for development.

3. Select appropriate CE building types and define their vertical massing.

4. Measure the associated jobs and housing projected from the demolished and proposed buildings.

5. Create an iterative feedback loop which continues to develop property until the target numbers are reached.

We diagrammed this path from the GIS data, reflecting Envision Tomorrow and Metroscope analysis, through the software platforms. The Envision Tomorrow development grids, property tax lots and existing building footprints are imported into CityEngine as shapes on separate layers, each annotated with relevant GIS data.

GIS

to

CityEngine

to

Python

to

CityEngine

to

Sketchup

to

Photoshop/Illustrator 


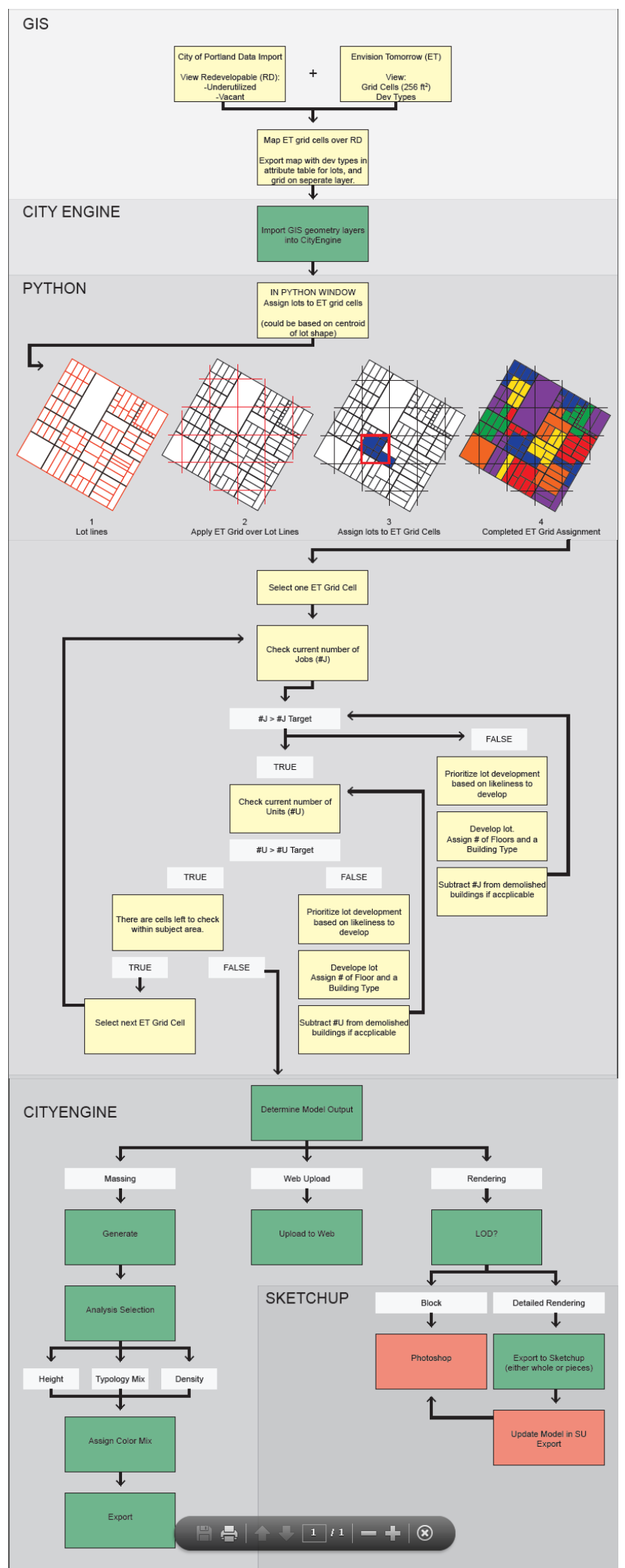

Figure 9: Workflow concept shows sequence of decision points and operations. 
Switching into the Python programming environment within CityEngine, the lots are first aligned to the development grid cells and assigned the corresponding development type. From this point we iteratively select and redevelop lots based upon the Envision Tomorrow goals for housing and jobs within each grid cell. The diagram shows a complete workflow for this process, which was partially implemented during the study. In the complete flow, a grid cell is selected and evaluated relative to its target job and housing numbers. If underdeveloped, a lot within the grid cell is chosen for redevelopment based upon a criteria function such as underutilization of the existing property. Existing buildings are removed from the lot and a new building type (e.g., single-family residential, office or industrial) assigned based on the building types mapped to the lot's associated grid's Development Type (e.g., commercial node, urban residential or light industrial). The new building is generated and the grid reassessed relative to the Envision Tomorrow goals. The iteration continues until all grid cells meet their target goals or no further development towards meeting those goals is possible.

A reduced version of this flow was implemented during the study in which tax lots in the district that have been identified as underutilized in terms of development value by the City of Portland were first sorted according to their assessed value per square foot and then divided into three groups. Starting with the most valuable lots first, each group was "redeveloped." First, large lots were subdivided into smaller building site units and a building type for each lot or sub-lot selected from the associated grid Development Type. The building type selection was based upon the percentage of building types appearing within the associated Development Type, but the prototype algorithm did not utilize job or housing target numbers to drive building type selection. The existing building masses were deleted from the lots and new masses created using CGA rules to generate forms appropriate to the building types. A snapshot of development after each group of lots was completed shows the overall redevelopment process as it occurred.
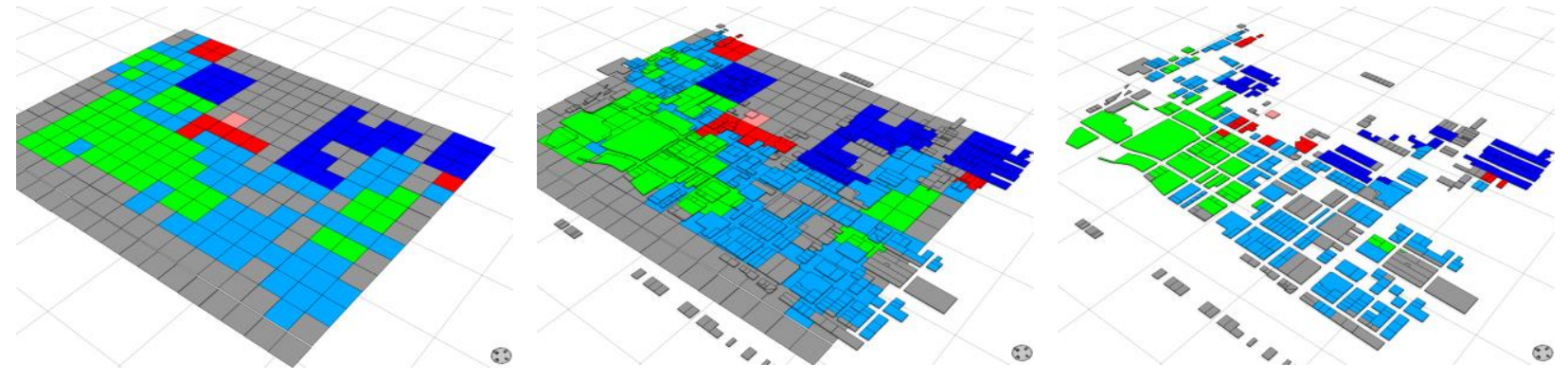

Figure 10: Metro's DevType gridcells from Envision Tomorrow get mapped onto City of Portland tax lots with current and potential valuations, then cell DevTypes are mapped to lots. 

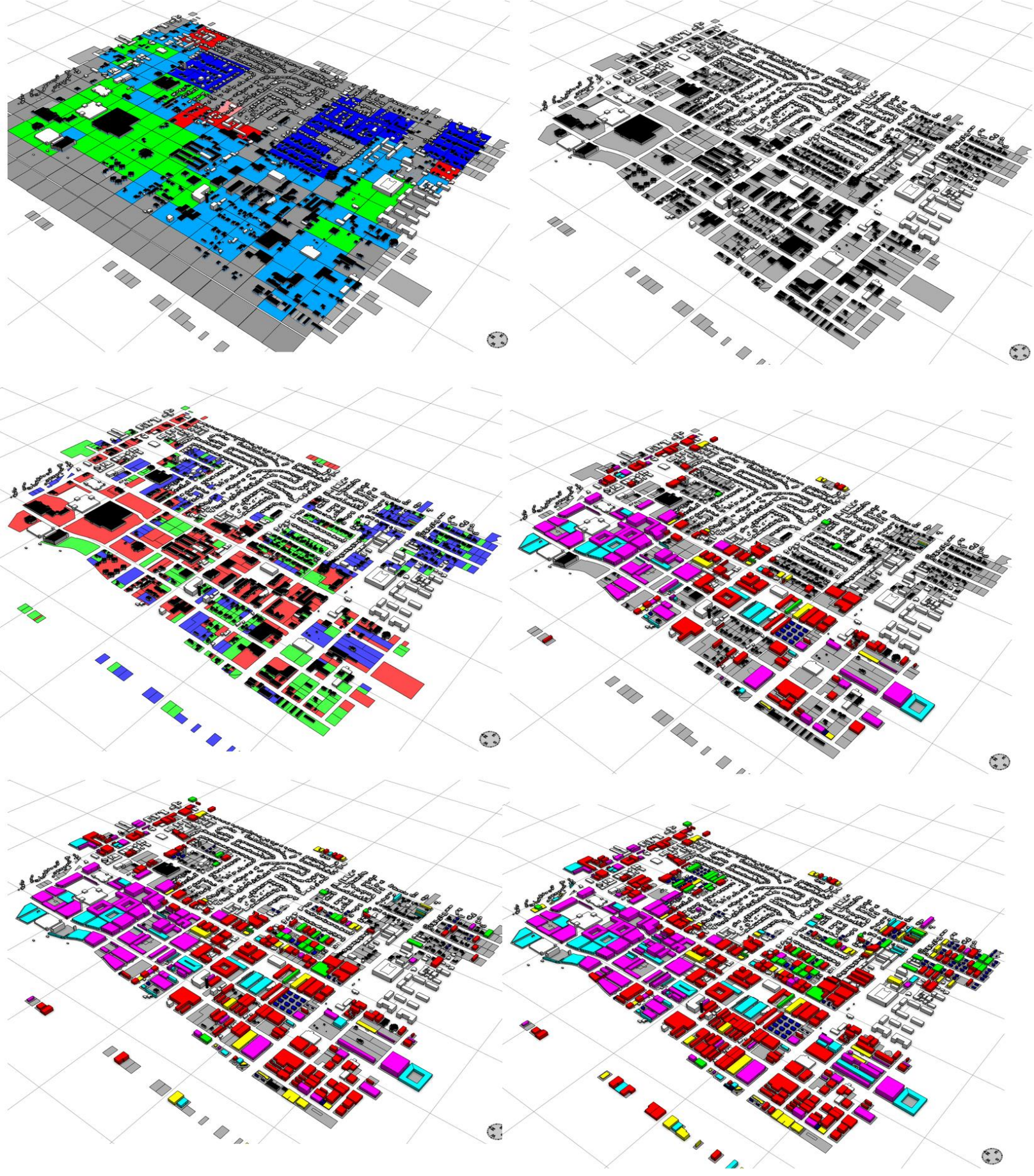

Figure 11. Data-driven building growth selects lots most likely to develop and iteratively adds massing according to the Development Type for the grid cell (upper right) until the number of housing units and jobs are met. 


\subsection{SOFTWARE PLATFORM ANALYSIS}

In developing the prototype workflow a great deal was learned about the different but overlapping strengths and capabilities of each of the three programming environments: GIS, Python and CityEngine CGA rule files. Each platform allowed certain operations to be performed easily; however, none of the three was sufficient to perform the entire process alone. The fact that the team had to power a user for each of the tools greatly facilitated the development of the workflow.

Specifically, each tool was used and had the following strengths and weaknesses:

\subsubsection{ArcGIS}

Used via the ArcGIS GUI to select and separate shapes into layers prior to importing into CityEngine.

Used for:

- 2D pre-processing to identify overlapping elements and separate shapes into groups to be assigned to different layers in CityEngine.

- Annotating shapes with initial data such as Development Types assigned to grid cells.

Strengths:

- Already the source format and tool for most of the data being analyzed.

- Existing, stable tool with a large feature set for manipulating 2D shapes.

- Strong existing tool knowledge and expertise.

Weaknesses:

- 2D work only.

Although ArcGIS provides additional custom programming capabilities, in this study all processing at this stage was done by hand, not automated.

\subsubsection{Python}

The most flexible of the programming environments, Python provided a general software language for data manipulation and creating the iterative redevelopment loop. Within CityEngine the development environment tended to be very brittle in that even minor syntax errors caused modules simply not to load, with no feedback regarding why or where the error was located.

Used for:

- Loading Envision Tomorrow data from Excel spreadsheets.

- Assigning Envision Tomorrow Development Types to grid cells.

- Aligning tax lots to grid cells and tagging with corresponding Development Types (each lot was assigned to one grid cell and development type; a grid cell could have zero, one or multiple lots assigned to it).

- Aligning existing building footprints to individual lots for redevelopment (each footprint could overlap with multiple lots, and each lot could have multiple footprints on it).

- Calculating lot value based on annotated data provided from GIS. 
- Sorting by value and selecting lots for redevelopment.

- Incrementally redeveloping lots, deleting existing building footprints that overlapped with them, assigning the correct CGA rules based on development and building type, and triggering the generation of the new buildings.

Strengths:

- Flexibility and capability to develop arbitrary computer algorithms, data structures and routines.

- Interpreted command environment allows incremental development of tasks and live interaction with the CityEngine model.

- Provides the path needed to load and utilize additional data sources such as Excel spreadsheet data.

Weaknesses:

- Brittle programming environment which proved challenging for development and debugging.

- Limited CityEngine API module support to date.

- Limited geometry support without an additional third-party package.

\subsubsection{CGA Rule Files}

This rule-based programming language specifically targets CityEngine shape generation and is extremely useful for the final stages of generating massing models. The language provides a feature-rich environment for shape selection and generation that would be cumbersome or impossible to duplicate in a traditional imperative programming environment such as Python.

Used for:

- Probability-based selection of alternative building types and shapes.

- Form generation.

- Sub-dividing large lots.

Strengths:

- Ease in creating massing forms.

- Ease in selecting alternative choices based on probability values. Weaknesses:

- Lack of input support for external data input.

- Specialist language and knowledge required.

\subsection{FURTHER DEVELOPING DATA-DRIVEN MANIPULATION}

While all of the pieces are in place to enable CityEngine's use as a data-driven visualization tool, the complexity of triple environment (GIS/Python/CGA) requires stabilization and refinement. With a complete Python environment and the command interpreter interface, it should be possible to quickly and interactively create data-driven views of urban landscapes. The primary hurdle to overcome is that of stabilizing the Python debugging environment and then building up a family of Python routines and CGA model files for repeated use.

From visual inspection, it appears that the current CityEngine workspace is based upon the powerful and extensible Eclipse Interactive Development Environment. Eclipse has Python development modules available and, using those, it might be possible to create a much more 
robust and complete programming and debugging environment for manipulating data and creating the needed iterative programming loops. Identifying a fast and robust 3D Python geometry package is also necessary to continue the work. CGA-rule files will continue to be the best mechanism for creating the actual building masses, but much of the data manipulation and rule assignment could be incorporated into the Python space and, from there, controlled by simple Excel spreadsheets specifying the alternative development scenarios and parameters.

\section{ISSUES: PLACE SPECIFICITY, PLANNING ABSTRACTION AND SOFTWARE FIT}

\subsection{SPECIFICITY: FROM VIRTUAL CITIES TO REAL NEIGHBORHOODS}

Our conceptual workflow for moving from GIS to CityEngine to Sketchup initially went smoothly when using small hypothetical example districts. When we began to apply this workflow to real data for a specific neighborhood in East Portland's Gateway district, then the nature of the project changed. While CityEngine can be used to quickly generate new idealized cities, working on an existing neighborhood is more complex. Sliver lots and small parcels might have to be aggregated to create usable lots. Associations have to be made between different kinds of data: Building footprints need to be tied with their lots, and lots matched to urban planning grid cells. This is further complicated by the fact that Metro and the City of Portland have made different choices in grid cell dimensions.

Because of its ability to create an archetypal urban form, we can imagine using CityEngine to create a more robust set of Development Type descriptions. CGA scripts could provide visual descriptions of abstract block types as 3D color-coded massing icons with housing and jobs quantities. The Development Types painted in Envision Tomorrow could then generate either Lego-block massing, whose colors reveal the development type, or a more photorealistic neighborhood view. The concept of being able to look back to the data behind the image by selecting a building is promising. We like being able to select a block and see DevType and some statistics, and being able to move between levels of detail - from Lego to building façade.

The challenges of bringing together different kinds of information can be addressed through a better teaming of those with skills in GIS, CE and SU, and exploiting their skills to better effect in solving these issues. A central data repository with a log system for reporting progress and communicating questions could streamline communication. GIS data will likely require some updating in the future if it is to be used in the CE user interfaces, and a true CE code developer will likely be necessary to fully exploit the wealth of GIS data available. If the data and codes ruling the data are effective, as examples have shown in other cities, there is no doubt that this can be an excellent method for creating powerful visualizations. 


\subsection{DEPICTING ABSTRACT PLANNING SCENARIOS}

Throughout the research, the team had difficulty pinning down how the general concept of three investment scenarios intended to reduce carbon emissions would translate into funding built amenities for a specific place. In part, this is due to the difficulty of predicting the implementation consequences of broad planning initiatives. For example, attractive inexpensive greenfield sites brought into the urban growth boundary can change the growth distribution and impede development of central areas, even in a high-growth scenario.

To develop the general theme of providing better access to public transportation and more "liveable cities," much research remains in understanding how a wide variety of actions can make a difference in the reduction of greenhouse gas emissions. The impact of these actions must first be better understood before the tangible differences shaping the individual experience in a place can be visualized.

The specific history of the location came into play when creating illustrations of Gateway as a trial area for the research. While the intention of the pilot illustrations was to show how an area could prosper from transit and other investments, Gateway is already well-served by public transportation, a key greenhouse gas emission reduction strategy. The area has been repeatedly identified as ripe for development due to a large investment in light rail transit, and its relatively low-real estate value in combination with a central location in the Portland metropolitan area. However, other market factors have deterred development of a more vibrant regional center as envisioned by the City of Portland's comprehensive plan.

As a pilot example, the Gateway location points out the difficulties in developing specific neighborhood street-corner visualizations. The planning process is abstract and makes it difficult to define desirable outcomes. While we want to show the kind of attractive retail shops, planting configurations, and benches that make an attractive pedestrian environment, they require investment and design decisions that are much further down the road from the initial planning. Therefore, the challenge of ambiguous content for the visualization is likely to exist for most neighborhood locations.

\subsection{UTILITY OF CITYENGINE FOR PLANNING VISUALIZATION}

In summary, we have shown that rigorous development forecasting can drive CityEngine's powerful parametric modeler to depict 3D land-use and transportation scenarios. It works very well for neighborhood scale planning at the abstract massing scale. Programming the detail needed for street-corner perspectives is both laborious and inappropriate to early planning visulization. We needed a substantial time investment to develop CGA building descriptions, adapt anomalous real-world GIS data and create the data-driven massing.

Currently, CE is more efficient at portraying alternatives for blank sites and has difficulty resolving the complexity of real-world data. Reflecting its European roots, it is more effective for dense urban settings than the typical suburban fabric with buildings independent of lots. A strong library of CGA building and streetscape elements would make the tool more effective in the hands of designers. 
While CityEngine's real-time rendering is laudable, visual standards for static images are very high. So the models require further processing for static illustrations, making it difficult to have them data-driven.

\section{CONCLUSION: UNITING DIVERSE PERSPECTIVES}

By showing different kinds of information, an ensemble of targeted images can build a case for a development scenario. Color-coded massing visualizations which indicate growth potential can complement more diagrammatic 2D maps and more evocative photographic references. As with all infographics and place-making visualizations, the challenge is very often one of simplifying vast amounts of information into a straightforward and clear message. The form of the message needs to be tuned to the audience and the scale of the information: building, street corner, neighborhood or region. The challenge of efficiently creating suitable representations will continue to be present in further research.

Because the software landscape is constantly evolving, this is a snapshot of an attempt to bring together diverse tools and expertise towards common purposes. In the future, we seek a more interactive way to communicate possibilities for urban growth and illustrate the look and feel of the spatial experience. We seek a simple interface for non-technical people in which we can add or subtract housing units and jobs, then see the consequences. The software could help us understand where to place a building based on the redevelopment potential, given an existing development model.

Overall, we need three legs of the stool. The economics from MetroScope, the DevType map sketching of GIS-based Envision Tomorrow, and the 3D parametric modeling of CityEngine need to come together, using the best of each. This project developed a dialogue between those with common interests coming from different perspectives. With a greater understanding of how the tools can work together, we can identify appropriate application challenges for further research. 


\section{LIST OF FIGURES}

Figure 1: Fregonese's Envision Tomorrow allows planners to paint Development types onto map gridcells.

Figure 2: Each Development Type corresponds to specific proportions of building types, building height, number of housing units and jobs, and transit activity. Graphic cards by Ryan Sullivan of Paste in Place graphics

Figure 3. CityEngine uses rules to generate streets from street centerlines, and buildings from lot footprints, leaving gaps from setbacks and right-of-ways.

Figure 4: Google Earth of existing (top) with CityEngine buildings (middle) and Photoshop (bottom)

Figure 5: Pedestrian perspective views exaggerate distortions of site photos captured from above and require supplementary foreground information. Right foreground shows unrealistic covered tree canopy.

Figure 6: Non-photorealistic illustration effects can be created by post-processing the images. Limited control over edge precision makes the techniques less appropriate for illustrating buildings. (See work of Dr.Jürgen Döllner and David Salesin)

Figure 7: Streetscape toolkit provides linear components for pedestrian friendly green streets

Figure 8: Scenarios A, B \& C with CityEngine buildings and streetscape elements. Lifting the viewpoint off the ground shows spatial organization better than ground level perspectives.

Figure 9: Workflow concept shows sequence of decision points and operations.

Figure 10: Metro's DevType gridcells from Envision Tomorrow get mapped onto City of Portland's taxlots with current and potential valuations, then cell DevTypes are mapped to lots.

Figure 11. Data-driven building growth selects lots most likely to develop and iteratively adds massing according to the Development Type for the gridcell (upper right) until the number of housing units and jobs are met. 


\section{REFERENCES}

Dr. Jürgen Döllner, Hasso Plattner Institute, University of Pottsdam, Lab tests how nonphotorealistic rendering techniques affect user perceptions of urban visualizations.

http://www.hpi.uni-potsdam.de/doellner/3dgi/

Metro, Creating livable streets: Street design guidelines for 2040

http://www.oregonmetro.gov/index.cfm/go/by.web/id=235

S. McElvaney, Geodesign: Case Studies in Regional and Urban Planning, ESRI Press, 2012.

http://esripress.esri.com

Portland Development Commission (PDC), Johnson Reid LLC and SERA Architects, Gateway Urban Design and Market Study, 2012.

http://www.pdc.us/Libraries/Gateway_Regional_Center/Gateway_Urban_Design_and_Market_S tudy_Report_pdf.sflb.ashx

Dr. David Salesin, University of Washington Seattle has pioneered non-photorealistic rendering techniques by careful observation and analysis of artists techniques.

http://salesin.cs.washington.edu/ 



\section{GOTREC \\ AND EDUCATION CONSORTIUM}

P.O. Box 751

Portland, OR 97207

OTREC is dedicated to stimulating and conducting collaborative multi-disciplinary research on multi-modal surface transportation issues, educating a diverse array of current practitioners and future leaders in the transportation field, and encouraging implementation of relevant research results. 